\title{
La imagen de Grecia en Schiller y Hölderlin: un horizonte utópico siempre por venir
}

\section{The Image of Greece on Schiller and Hölderin: an utopian horizon}

\author{
SEBASTIÁN GÁMEZ MILLÁN \\ UNED
}

Recibido: 15/06/2017 Aceptado: 19/12/2017

\begin{abstract}
RESUMEN
La imagen de la Grecia de Pericles ha sido un ideal de ciudad durante multitud de generaciones. Durante el Romanticismo, autores como Schiller y Hölderlin, entre otros, la concibieron desde una perspectiva filosófica de tal modo que ha configurado hasta cierto punto la imagen que hemos recibido de Grecia. Más allá de ello, y aun reconociendo que se trata de un ideal regulativo de la razón, no deja de ser un modelo filosófico con valores artísticos y éticos-políticos, como su idea de belleza, civismo y cosmopolitismo, que no cesan de interpelarnos en forma de horizonte utópico siempre por venir.
\end{abstract}

\section{PALABRAS CLAVE}

GRECIA; ARTE; MODELO; UTOPÍA; ÉTICA-POLÍTICA

\begin{abstract}
The image of the Greece of Pericles has been an ideal city for many generations. During the Romanticism, authors like Schiller and Hölderlin, among others, conceived it from a philosophical perspective in such a way that it has configured to some extent the image that we have received from Greece. Beyond that, and even admitting that it is a regulative ideal of the reason, it is still a philosophical model with artistic and ethical-political values, as its idea of
\end{abstract}


beauty, civility and cosmopolitanism, which do not cease to question us in the form of utopian horizon always to come.

KEYWORDS

GREECE; ART; MODEL; UTOPIA; ETHICAL-POLITICAL

Quizá no exista un espacio geográfico a la vez que mitológico tan citado y soñado por los filósofos como la Grecia de Pericles del siglo V a. C., donde surgieron la filosofía, la historia y la democracia en Occidente, y las artes y las ciencias alcanzaron una época de esplendor sin igual. Como señalara el prestigioso helenista Maurice Bowra, «constituye un lugar común decir que el mundo moderno debe los elementos más duraderos y valiosos de su civilización a la región del Mediterráneo, y que lo que Palestina contribuyó a la religión y la moral, o Roma al derecho y la política, Grecia lo aportó a las ciencias y las artes (...) habitado por unos 200.000 hombres libres, contribuyó al pensamiento, la literatura y las bellas artes con aportaciones de magnitud sin precedentes, y con tal maestría que gran parte de ellas no ha sido nunca sustituida o superada». 1

Se diría que desde hace siglos uno de los hábitos de distintas generaciones de filósofos es rememorar y soñar aquella Grecia. La hemos soñado tanto que albergo dudas acerca de si podemos regresar a la Grecia real de aquella época esplendorosa entre tantos estratos de sueños con la que la hemos construido, idealizado y seguramente magnificado. Pero tal como se preguntaba Paul Valéry en Breve epistola sobre el mito: «¿Qué sería, pues, de nosotros, sin la ayuda de lo que no existe?»

¡Qué importa si no podemos regresar a aquella Grecia real, si aún podemos seguir soñando con esa Grecia que es un horizonte utópico siempre por venir, un modelo de civilización, por supuesto que criticable y perfectible! Que no sea «real», o que no podamos estar completamente seguros de ello, no significa que no nos sea valiosa o útil su idea e incluso que no sea conveniente como horizonte utópico por venir. Hay ideales regulativos de la razón que producen profundos efectos de realidad y efectos en la realidad, de manera que sería absurdo negar el poder transformador de los mismos.

Entre las distintas generaciones de pensadores que han soñado Grecia hay una generación a caballo entre la Ilustración y el Romanticismo que la soñó de una forma tan singular que todavía hoy, unos dos siglos después, no dejamos de soñarla bajo la configuración que algunos de ellos trazaron. Me refiero, claro está, a Winckelmann, Goethe, Schiller, Hölderlin, Schlegel, Moritz, Lessing,

1 Maurice Bowra, «Atenas en la época de Pericles», reunido en A. Toynbee, Ciudades de destino (De Atenas a Nueva York), trad. G. Castro, Madrid, Sarpe, 1985, pp. 59 y 60. 
Herder... A continuación me centraré en la imagen de Grecia en Schiller y Hölderlin y en algunas de las posibles repercusiones que estas ideas podrían tener sobre nuestra actualidad.

Como ha indicado Safranski, «desde Winckelmann se disputó en Alemania sobre el carácter modélico de la antigüedad griega y, en menor medida, de la antigüedad romana. Se trataba de una continuación de la Querelle des anciens et des modernes, una disputa que dirimió la Francia intelectual de finales del siglo XVII, y en la que abordaban el tema de si el arte y la literatura «modernos» representaban un progreso frente al mundo antiguo, o bien debían seguir aprendiendo del gran pasado. En Francia la disputa se resolvió a favor de una 'modernidad consciente de sí misma. Pero cuando medio siglo más tarde se produjo de nuevo el debate en Alemania, dominaron los 'clasicistas'». ${ }^{2}$

Esta querella acerca de si el arte y la literatura «modernos» representa un progreso respecto, no ya «el mundo antiguo», sino con respecto a «lo clásico», es una cuestión que no ha dejado ni dejará de interpelarnos, no solo porque a partir de ella podemos establecer la medida del «progreso», uno de los grandes relatos ilustrados que parecen habérsenos desmoronado con la denominada «postmodernidad», ${ }^{3}$ sino también porque a partir de ello podemos asimismo calibrar el grado de nuestra civilización.

Después de recordar, con Zbigniew Herbert, que «lo opuesto de lo clásico no es lo romántico, sino lo bárbaro», J. M. Coetzee ha declarado que «la función de la crítica viene definida por el clásico: la crítica es aquella que tiene la obligación de interrogar al clásico (...) Tal vez este tipo de crítica sea uno de los instrumentos de la astucia de la historia». ${ }^{4}$ Como seres históricos, tenemos que conocer nuestro pasado para serlo y para saber elegir cuál nos conviene, pues el tiempo histórico no es una línea que avanza sin tregua hacia el progreso, como se lo ha representado de manera tradicional, sino que constantemente se manifiestan en un mismo espacio geográfico y cultural diferentes estratos de la historia, sin duda unos más civilizados que otros.

2 R. Safranski, Schiller o la invención del idealismo alemán, trad. Raúl Gabás, Barcelona, Tusquests, 2011, p. 278.

3 Véase J. F. Lyotard, La condición postmoderna, trad. Mariano Antolín Rato, Barcelona, Planeta, 1989. Otras sugerentes interpretaciones sobre el debate modernidad-postmodernidad se encuentran en S. Toulmin, Cosmópolis. El trasfondo de la modernidad. Trad. Bernardo Moreno Carrillo, Barcelona, Península, 1990; y en Rosa Ma Rodríguez Magda, Transmodernidad, Barcelona, Anthropos, 2004.

4 J. M. Coetzee, «¿Qué es un clásico? Una conferencia», reunido en Costas extrañas. Ensayos 1986-1999, trad. Pedro Tena, Barcelona, Debate, 2010, pp. 28 y 29. 
La cultura, estar cultivado, no significa saber con precisión una serie de nombres y fechas, no significa ser erudito, más bien, como indicara Hannah Arendt, una persona culta es «la que sabe cómo elegir compañía entre los hombres, entre las cosas, entre las ideas, tanto en el presente como en el pasado». ${ }^{5}$ Por tanto, la cultura está íntimamente vinculada con la libertad, pero la libertad no es algo dado simplemente; se crea y se recrea y se conquista continuamente por medio de cómo pensamos y actuamos.

Entre los románticos franceses la nostalgia por lo absoluto de aquella Grecia con la que soñaban Goethe, Schiller y Hölderlin no alcanzó tales extremos. ${ }^{6}$ Pero tampoco su incesante vigencia, como veremos. He aquí el peligro y la salvación de los sueños y de las utopías. Entre estos polos nos dirimiremos y es probable que no hayamos todavía resuelto la cuestión, entre otras razones, porque no podemos dejar de soñar, aunque sepamos que «los sueños, sueños son», como señalara un dramaturgo del siglo de Oro español que en ciertos momentos parece anticipar el Idealismo.

La imposibilidad de encontrarse satisfechos con el presente y lo que les rodea.

¿No es este uno de los sentimientos característicos del temperamento romántico? «Baudelaire, que describe a esos enamorados de los viajes como a insatisfechos ('Y el deseo les hacía siempre inquietos'), a los que sólo la muerte colmará con su suprema incógnita. (...) Shelley, en la elegía que llora la muerte de Keats, llama a Byron 'el Peregrino de la Eternidad'. Childe Harold, y el propio Alastor de Shelley, y el Endimión de Keats, son todos, en efecto, peregrinos en busca de una unidad casi mística con la naturaleza, con un yo femenino que los completase, o con la divinidad». ${ }^{7}$ Es una sed de infinito, una sed de absoluto que no se encuentra en este mundo. ${ }^{8}$ De ahí que la búsqueda esté condenada al fracaso, salvo que la propia búsqueda no está exenta de experiencias límites que pueden saciar hasta cierto grado lo dionisíaco que habita en cada uno de nosotros y, de paso, enriquecer el camino.

Paradójicamente, ¿no es lo contrario a esta característica romántica de imposibilidad de sentirse satisfechos con el presente uno de los rasgos que estos pensadores idealistas admiraban del espíritu griego clásico? En su re-

5 H. Arendt, «La crisis en la cultura: su significado político y social», reunido en Entre el pasado y el futuro. Ocho ejercicios de filosofia politica, trad. Ana Poljak, Barcelona, Península, 2003, p. 345.

6 H. Peyre, ¿Qué es verdaderamente el Romanticismo? Trad. Marcial Suárez, Madrid, Doncel, 1972, p. 141.

7 H. Peyre, 1972, op. cit., pp. 130 y 131.

8 Una aguda crítica a la búsqueda del absoluto, ya sea por medio de la creación artística como por medio del amor, puede leerse en T. Todorov, Los aventureros del absoluto, trad. José María Ridao, Barcelona, Galaxia Gutenberg-Círculo de Lectores, 2007. 
trato sobre Winckelmann, escribe Goethe a propósito de este espíritu griego clásico: «Aquello que sucedía era lo único que para ellos tenía valor, así como para nosotros sólo parece tenerlo en algún grado aquello que se piensa o se siente. (...) Todos se atenían firmemente a lo próximo, a lo verdadero, a lo real, e incluso los frutos de su fantasía eran de carne y hueso». ${ }^{9}$ Por tanto, como ha resumido Pierre Hadot, «sus rasgos comunes son la confianza en uno mismo, la acción en el presente, la admiración de los dioses como obras de arte, la sumisión al destino superior».. ${ }^{10}$

¿Eran conscientes estos pensadores de que cuando soñaban con aquella Grecia no estaban más que soñando? Cuando Schiller escribe en 1788 «Los dioses de Grecia», según Safranski:

«Sabe con toda evidencia que la realidad de la antigüedad griega no coincide con la imagen genérica del estado estético del mundo. No aspira a la descripción correcta de una época histórica irremediablemente desaparecida; más bien, busca un tipo básico para una comprensión alternativa del mundo, un tipo que pueda contraponerse a la modernidad. Y en esa búsqueda imaginó el 'país de fábulas' de la antigüedad griega con el propósito de ampliar el pensamiento». ${ }^{11}$

Sin ideas ni ideales, como esta Grecia de Schiller, sin el condicional («si...») que abre las puertas más allá de lo que existe, sin las creaciones artísticas, sin utopías ético-políticas, nuestro mundo se reduciría únicamente a lo que sucede de facto, de manera que no habría una comprensión alternativa del mundo, lo que nos impediría comparar, ensayar, experimentar y, en suma, elegir, que a su vez reduce nuestros márgenes de libertad. Estaríamos ante un mundo similar al que concibieron los miembros del Círculo de Viena, inspirados en una parte del Tractatus de Wittgenstein, es decir, solo admitiríamos como válidas las proposiciones que pueden verificarse naturalmente.

Fue este poema de Schiller sobre los dioses de Grecia el que inspiró a Hölderlin algún tiempo después su Grecomanía. Safranski dice diez años más tarde, ${ }^{12}$ pero en sus Poemas de juventud, fechados entre 1789 y 1794, ya encontramos poemas que tienen a Grecia como el ideal con el que despertar

9 J. W. Goethe, «Winckelmann», en J. J. Winckelmann, Historia del arte en la Antigüedad, trad. Manuel Tamayo Fraijo, Barcelona, Folio, 2002, p. 11.

10 P. Hadot, No te olvides de vivir. Goethe y la tradición de los ejercicios espirituales, trad. María Cucurella Miquel, Madrid, Siruela, 2010, p. 27. P. Hadot recibió reconocimiento internacional con su reinterpretación de la filosofía griega clásica como acción transformadora sobre sí mismo, interpretación que luego ha ido explicando en pensadores no solo antiguos, como Plotino o Marco Aurelio, sino también modernos, como Goethe o Wittgenstein, entre otros.

11 R. Safranski, 2011, op. cit., p. 280.

12 R. Safranski, 2011, op. cit., p. 282. 
un nuevo humanismo y un nuevo ser humano: «Grecia» o «Hércules» son dos de ellos. El primero se abre con estos hermosos versos:
«Bajo la sombra de los plátanos, donde el Iliso corría entre las flores, los jóvenes soñaban con la gloria; donde Sócrates conquistaba los corazones y Aspasia pasaba entre los mirtos, mientras los clamores de un gozo fraterno resonaba en el Ágora ruidoso, mi Platón forjaba paraísos». ${ }^{13}$

De otro modo, no mediante la filosofía, pero sí por medio de la poesía, Hölderlin también estaba forjando un paraíso (y su consiguiente infierno acaso). Si bien a juicio del poeta alemán, «la poesía es el principio y el fin de la filosofía», tal vez primero porque sin poesía entendida como creación tampoco hay filosofía; y, segundo, porque como señala Hölderlin al final de su poema Andenken, «lo permanente lo instauran los poetas», verso que le gustaba rememorar a Heidegger para añadir que «la poesía es el fundamento que soporta la historia» ${ }^{14}$ y que «poético» es asimismo el fundamento de la existencia humana, ya que «poéticamente es como el hombre habita esta tierra».

Esa sed de infinito y absoluto que se refleja en el amor, en la creación, en la muerte o en la búsqueda de paraísos lejanos y tal vez inexistentes a la que apuntábamos antes como una de las características principales del Romanticismo se percibe claramente en versos posteriores de «Grecia».

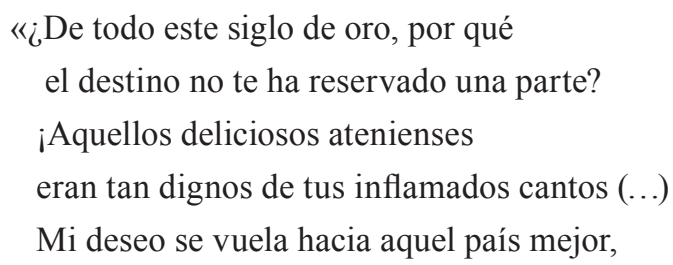

13 Hölderlin, Poesía completa, Barcelona, Ediciones 29, 1997, p. 27.

14 M. Heidegger, Hölderlin y la esencia de la poesía, recogido en Arte y poesía, trad. Samuel Ramos, México, F. C. E., 1995, p. 139. Sobre estas cuestiones de Heidegger con la poesía y la mitología es sugerente la lectura de Hugo Mujica, La palabra inicial. La mitología del poeta en la obra de Heidegger, Madrid, Trotta, 1995. 


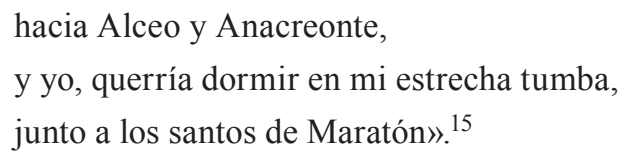

La obra de Hölderlin, pues, es inconcebible sin su amor por esta Grecia que no es tanto histórica como poética y mitológica, y con la que configura un horizonte utópico que siempre está por venir. A esta Grecia le dedicará Hiperión, Empédocles, El Archipiélago y numerosos poemas. Como había anticipado en un breve texto anónimo y decisivo, atribuido a Hegel, Schelling y Hölderlin, pero al parecer redactado por este último, El más antiguo programa de sistema del idealismo alemán (1796): «La idea que lo une todo es la idea de Belleza, tomada la palabra en el más alto sentido platónico. Estoy convencido de que el más elevado acto de la Razón, en cuanto que ella abraza todas las ideas, es un acto estético, y de que la Verdad y el Bien sólo en la Belleza se hallan hermanados»». ${ }^{16}$

Son palabras que tendríamos que seguir rumiando, al igual que las que ha escrito George Santayana: «Entre los griegos, la idea de felicidad era estética y la de belleza era moral; y esto no porque los griegos estuvieran confundidos, sino porque eran civilizados». ${ }^{17}$ Me pregunto hasta qué punto el fenómeno de lo kitsch y la consecuente degradación de valores estéticos, morales y cívicopolíticos se encuentra vinculado con la disociación de la belleza y de la moral, tal como penetrantemente analizara uno de los grandes escritores del pasado siglo, Hermann Broch. ${ }^{18}$

Al afirmar Kant al término de la Dialéctica del discernimiento estético que «lo bello es el símbolo del bien moral», ${ }^{19}$ el filósofo estaba restaurando un puente derruido entre lo estético y lo ético, y quién sabe si también lo político, pues

15 Hölderlin, 1995, op. cit., p. 28.

16 Antonio Alegre Gorri, «Hölderlin: el poeta-filósofo», reunido en Historia del pensamiento, V. III Alemania toma la palabra, Barcelona, Orbis, 1983, p. 120.

17 Citado por Fernando Savater en «Concepto y estética en George Santayana», reunido en F. Savater, Instrucciones para olvidar el Quijote. Y otros ensayos generales, Madrid, Taurus, 1995, p. 66.

18 Me refiero a sus ensayos «Algunas consideraciones acerca del problema del kitsch»y «El mal en el sistema de valores del arte», ambos recogidos en H. Broch, Poesía e investigación, trad. Ramón Ibero, Barcelona, Barral, 1974.

19 Kant, Crítica del discernimiento, trad. R. R. Aramayo y Salvador Mas, Madrid, Antonio Machado, 2003, p. 327. 
sin juicio de gusto estético y ético está por ver que se pueda crear una comunidad política decente. Schiller admiraba la filosofía de Kant y, en particular, la Crítica del juicio hasta tal punto que su obra filosófica más ambiciosa y perdurable, Cartas sobre la educación estética del hombre, puede considerarse un diálogo con ella.

No sé si, como mantiene Amelia Valcárcel a partir de las reflexiones de Kant y Schiller, «la estética es el fundamento de posibilidad de la ética y fundamento en dos sentidos. Fundamento genético, porque antes estuvo el adorno que la voluntad buena; y fundamento absoluto, porque, si la ética es libertad, la estética es la libertad». ${ }^{20}$ Mas, en todo caso, ambas se manifiestan en lo bello, requieren de ciertos márgenes de libertad para ser juzgadas y aspiran a ampliar nuestras libertades. En ocasiones, como advirtiera Wittgenstein bajo una concepción cercana a la griega clásica, «ética y estética son una y la misma cosa». No obstante, la identidad entre ambos términos no es siempre plena (quizá hay una tensión dialéctica irresoluble), pues una de las funciones del arte y de la estética consiste precisamente en arremeter contra los límites de lo que se considera moralmente aceptado, ensanchando el espacio de la ética y de la libertad.

Schiller busca en el arte y en la estética el fundamento de la libertad ética y política: «hay que emprender el camino a través de lo estético para resolver prácticamente aquel problema político, porque es a través de la belleza como se llega a la libertad». ${ }^{21}$ Antes, en esta segunda carta, se pregunta si la obra artística más perfecta de todas no será la construcción de una verdadera libertad política. ${ }^{22}$ Pero como en todo diálogo que se aprecie, hay una dimensión crítica:

«Por consiguiente, no basta que toda la ilustración del entendimiento merezca consideración solo en tanto que actúa sobre el carácter; en cierto modo, también procede del carácter, porque el camino hacia la cabeza tiene que abrirse a través del corazón. Educar la sensibilidad es, pues, la necesidad más urgente de la época, no solo porque se convierte en un medio para hacer eficaz para la vida el perfeccionamiento del saber, sino incluso porque contribuye a ese perfeccionamiento» ${ }^{23}$.

Educar la sensibilidad y las formas de sentir es un modo de ilustración en el que Kant apenas repara y que, sin embargo, sí consideraron David Hume y Lichtenberg. Nos preguntábamos antes si es posible una comunidad política

20 A. Valcárcel, Ética contra estética, Barcelona, Crítica, 1998, p. 98.

21 Schiller, Cartas sobre la educación estética del hombre, trad. Vicente Romano García, Madrid, Aguilar, 1981, p. 30.

22 Schiller, 1981, op.cit., p. 27.

23 Schiller, 1981, op.cit., p. 56. 
decente sin juicio de gusto estético y ético por parte de los ciudadanos. Muy difícilmente. De hecho, una de las características de aquella Grecia clásica fue el gusto aristocrático. Como señala el helenista Maurice Bowra, «las características poco comunes de la democracia se pueden comprobar por ciertas cualidades que no suelen encontrarse en sociedades de ese tipo. En primer lugar, Atenas había heredado una tradición aristocrática de buen gusto y elegancia». ${ }^{24}$

Otro aspecto que merece resaltarse de aquella Grecia es su cosmopolitismo. En «Las grandes urbes y la vida del espíritu», el sociólogo y pensador Georg Simmel ha escrito que «para la gran ciudad es decisivo esto: que su vida interior se extienda como crestas de olas sobre un ámbito nacional o internacional más amplio». ${ }^{25}$ Antes que en el estoicismo romano tardío (Epicteto, Séneca, Marco Aurelio), las fuentes de procedencia del cosmopolitismo hay que rastrearlas por aquella Grecia entre individuos como Sócrates o Diógenes, entre otros. «Ciudadano del mundo», indica la etimología de «cosmopolita», ${ }^{26}$ precisamente porque se trata de individuos que están abiertos a reconocer lo excelente, provenga de donde provenga, a diferencia de patriotismos, nacionalismos, provincianismos y cosmopaletismos. Además de a Kant, Schiller es fiel al espíritu de aquella Grecia que él soñara, pues como ha señalado el sociólogo Richard Sennet:

«en griego, la palabra poiein significa 'hacer'. Poiesis deriva de esa raíz y significa el acto creativo. Mucho más que Esparta, la cultura de la Atenas de Pericles constituía un himno al ideal de la poiesis, la ciudad concebida como una obra de arte. El razonamiento forma parte de ese acto creativo, tanto si es científico como político. Algunos escritores antiguos denominaron a la política democrática auto-poiesis, una auto-creación política en permanente mutación». ${ }^{27}$

El paralelismo entre arte y ética y política a partir de la auto-creación no es fortuito: lo logren o no, cosa que también depende de nuestra recepción de la obra, el arte aspira a transformarnos, del mismo modo que la ética y la política: acceder a otra forma de ser, bien por la fuerza de la expresión artística,

24 M. Bowra, 1985, op. cit., p. 65.

25 G. Simmel, «Las grandes urbes y la vida del espíritu», recogido en El individuo y la libertad. Ensayos de crítica de la cultura, trad. Salvador Mas, Barcelona, Península, 2001, p. 391.

26 Como es sabido, durante la Ilustración Kant, que no suele perder de vista la universalidad, es uno de los que reivindica este concepto; por ejemplo, en «Ideas para una historia universal en clave cosmopolita», recogido en I. Kant, Ensayos sobre la paz, el progreso y el ideal cosmopolita, trad. Concha Roldán Panadero y R. Rodríguez Aramayo, Madrid, Cátedra, 2005, pp. 33-49. En nuestros días, uno de los pensadores que más y mejor ha reivindicado este concepto es K. A. Appiah, en obras como Cosmopolitismo. La ética en un mundo de extraños, Madrid, Katz, 2007.

27 R. Sennet, Carne y piedra. El cuerpo y la ciudad en la civilización occidental, trad. César Vidal, Madrid, Alianza, 2002, p. 92. 
bien por el poder de la interpelación y de la persuasión ético-política. Tanto el arte, como la ética y la política surgen a partir de ciertos márgenes de libertad, pero aspiran a ampliarlos por el buen ejercicio de cada una de estas disciplinas.

Sin duda, un estado político que cumpliera con los Derechos Humanos, permitiera el libre desarrollo de la naturaleza humana y suscitara el bien común (me consta que esto no es de este mundo, pero, como saben, estamos en y con los idealistas alemanes), produciría mayores y más beneficiosos efectos performativos que la mayor obra de arte jamás soñada por artista alguno. La política es la obra de arte colectiva por antonomasia, y por eso mismo es la que puede crear o destruir más libertades.

Una de las funciones del arte es mantener en forma de símbolo los ideales de los ciudadanos, faros que iluminan lo que somos al tiempo que iluminan lo que deberíamos ser. En la Grecia de Pericles posiblemente ninguna obra de arte ejercía esta función como el edificio que coronaba la ciudad: «la ubicación del Partenón en la ciudad simbolizaba su valor cívico colectivo. Visible desde muchos lugares de la ciudad, desde los distritos nuevos o en expansión al igual que desde los barrios viejos, la imagen de la unidad resplandecía bajo el sol». ${ }^{28}$ Maurice Bowra recuerda que

«Aun en su ruinoso estado actual, los grandes edificios de la Acrópolis se levantan como un monumento impresionante y majestuoso a la grandeza de Atenas. (...) expresión de lo que el pueblo ateniense creía y esperaba en relación a sí mismo como un todo. Si glorificaban el poder, no se trataba del poder individual del algún hombre, sino del de un pueblo y de su diosa, y la expresión de este poder no era ostentosa ni jactanciosa, sino disciplinada por algo típicamente helénico $\mathrm{y}$ ateniense». ${ }^{29}$

De este modo las obras de arte ofrecen un testimonio imprescindible para conocer las diversas culturas, ya que a través de sus obras podemos aproximarnos a cómo se veían a sí mismos y los ideales que aspiraban alcanzar. «En las concepciones griegas de la ciudad se detectaban dos juicios de valor: que las ciudades deben construirse a medida del hombre y que deben promover el conocimiento mutuo entre los ciudadanos y su participación en la comunidad. La finalidad de la polis fue resumida por Sófocles: 'La ciudad es la gente'». ${ }^{30}$ Es difícil no estar de acuerdo con el dictum de Sófocles sobre quién es esencialmente la ciudad, sin embargo, las políticas-económicas de gran parte de

28 R. Sennet, 2002, op. cit., p. 41.

29 M. Bowra, 1985, op. cit., p. 70.

30 L. Racionero, El Mediterráneo y los bárbaros del Norte, Barcelona, Plaza y Janés, 1996, p. 61 
los gobiernos del mundo instrumentalizan y cosifican a los ciudadanos, a pesar de que son estos los principales artífices de las ciudades.

El sociólogo Richard Sennet ha recordado que «ningún pueblo valoró de manera más consciente la cultura cívica que los atenienses: 'humano' y 'polis' eran términos intercambiables»». ${ }^{31}$ De este modo la altura de la humanidad se podía medir por su grado de civismo y su sentido de la comunidad, y al revés, el grado de civismo y el sentido de la comunidad de un individuo nos informaba acerca de su humanidad. Y estos lazos, si no lo habían creado las artes, lo sostenían estas, pues como recuerda la helenista Jacqueline de Romilly, «la tragedia no deja de repetir la misma idea, poniendo el bien de la ciudad por encima de todo lo demás»». ${ }^{32}$ Esto es, lo comunitario por encima de lo individual en el orden jerárquico de los valores, lo que no significa ni implica que lo aplaste: puede y debe respetarse lo individual a la vez que se reconoce que la comunidad nos constituye. Todavía más: como señala Alasdair MacIntyre, con la tragedia había tenido lugar una profunda transformación, puesto que

«en Homero la cuestión del honor es la cuestión de qué se le debe a un rey; en Sófocles la cuestión del honor se ha convertido en la cuestión de qué se le debe a un hombre. No obstante, no parece accidental que la pregunta de qué se le debe a un hombre se plantee en el contexto ateniense, y no en el tebano o el corintio, por no mencionar a los bárbaros. Caracterizar al hombre bueno es, en parte decisiva, caracterizar la relación que ese hombre mantiene con los demás, y al considerar estas relaciones, la mayoría de poetas y filósofos no distinguen lo que es humano y universal de lo que es local y ateniense». ${ }^{33}$

Quizá porque como indicara Aristóteles en la Poética, la poiesis es universal o bien aspira a elevar lo particular a lo universal, al igual que los razonamientos. Uno de los más doctos conocedores del espíritu griego clásico, Werner Jaeger, escribió: «los griegos buscaron la «ley» que actúa en las cosas mismas y trataron de regir por ella la vida y el pensamiento del hombre. El pueblo griego es el pueblo filosófico por excelencia. La «teoría» de la filosofía griega se halla profundamente conectada con su arte y su poesía (...) Lo universal, el logos, es, según la profunda intuición de Heráclito, lo común a la esencia del espíritu, como la ley lo es para la ciudad». ${ }^{34}$

31 R. Sennet, 2002, op. cit., p. 395.

32 Jacqueline de Romilly, El tesoro de los saberes olvidados, trad. Manuel Serrast Crespo, Barcelona, Península, 1999, p. 154.

33 A. MacIntyre, Tras la virtud, trad. Amelia Valcárcel, Barcelona, Crítica, 2004, p. 169.

34 W. Jaeger, «Posición de los griegos en la historia de la educación humana», en W. Jaeger, Paideia, trad. Joaquín Xirau y Wenceslao Roces, Madrid, F. C. E., 2001, p. 10. 
Lo universal puede estar en la naturaleza, pero dada la ineludible subjetividad de las cuestiones humanas, más difícilmente se encontrará en lo antropológico. Sin embargo, para no pocas cuestiones (como la justicia o la igualdad, caras de una misma moneda) sentimos que es lo que debe ser. Por ello, «Atenas es alabada porque ella par excellence muestra la vida humana como debe ser». ${ }^{35} \mathrm{Y}$ quizá esta sea una de las razones por las que, como indicara Savater, «la Grecia actual no es ni más ni menos que una nación entre las demás, como las restantes, con sus perplejidades y sus miserias, mientras que la otra Grecia, la asentada ya por siempre en el esplendor terrible y profético de nuestros orígenes, es la forma misma de nuestro destino en cuanto ciudadanos de este mundo». ${ }^{36}$ Sospecho que la tensión irresoluble entre lo que es y lo que debe ser, entre la naturaleza y lo ético-político, no cesará de interpelarnos a lo largo de la historia.

En 1799 Schiller les declara a los artistas: «iLa dignidad de la humanidad está en vuestras manos, conservadla!». ${ }^{37}$ En otras palabras Schiller les está reclamando a los artistas que no dejen de soñar y expresar sus sueños, pues así, y quizá solo así, podremos preservar lo ideal para mantener, en el horizonte, siempre elevada, la humanidad. Si los derechos humanos son, de acuerdo con la definición de Antonio Pérez Luño, que los contempla desde una perspectiva dialéctica, iusnaturalista a la vez que positivista, «el conjunto de facultades e instituciones que en cada momento histórico concretan las exigencias de dignidad, libertad e igualdad que han de ser reconocidas positivamente por ordenamientos jurídicos nacionales e internacionales», una de las funciones del arte es crear símbolos que mantengan los ideales de valores como la dignidad, la libertad y la igualdad vivos.

Inspirándose en Lecciones sobre el destino del sabio, de Fichte, Schiller escribe en Cartas sobre la educación estética: «Se puede decir que todo individuo humano lleva en sí la planta de un ideal puro, siendo el gran deber de su existencia concordar en todos sus cambios con su unidad invariable». ${ }^{38}$ Se podría parafrasear añadiendo que casi toda ciudad lleva en sí un ideal de aquella Grecia mítica, y que su deber es aproximarse aun a sabiendas de que no la alcanzará nunca de manera definitiva, puesto que se trata de un horizonte utópico que siempre está por venir. Pero en nuestro sostenido esfuerzo por alcanzarlo, eludiendo cualquier forma de utopía regresiva y totalitaria, podemos dignificarnos como seres humanos.

35 A. MacIntyre, 2004, op. cit., p. 169.

36 F. Savater, «Nuestra Grecia», op. cit., 1995, p. 250.

37 J. L. Reina Palazón, Antología esencial de la poesía alemana, trad. J. L. Reina Palazón, Madrid, Espasa, 2004, p. 161.

38 Schiller, op. cit. 1981, p. 34. 
Sebastián Gámez Millán, profesor de filosofía del IES «Valle del Azahar» y de la UNED.

Lineas de investigación

Estética y teoría del arte, filosofía y literatura, antropología, ética y política.

Publicaciones recientes

Cien filósofos y pensadores españoles y latinoamericanos, Madrid, Ilusbooks, 2016.

La condición humana a través del arte, Madrid, Ilusbooks (en imprenta).

Un viaje por el tiempo, Premio Ateneo-UMA de Divulgación Científica 2016

(una editorial lo valora para su publicación).

Email: sebastiangamezmillan@gmail.com 
